\title{
The "zipline" technique for endoscopic transpapillary biliary biopsy
}

Endoscopic transpapillary biopsy has been the cornerstone of tissue acquisition from the biliary epithelium $[1,2]$. However, targeting biliary lesions using standard biopsy forceps is occasionally difficult [3], and wire-guided biopsy for-

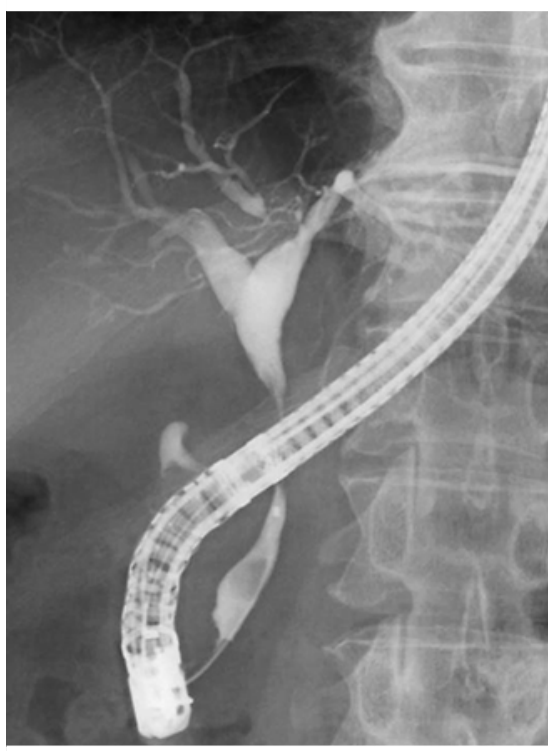

- Fig. 1 Cholangiogram delineating a stricture of the mid bile duct with irregularity of the distal bile duct. ceps are not commonly available. Herein, we present a technique for biliary biopsy with a simple modification of a widely used biopsy forceps.

A 67-year-old man was admitted with obstructive jaundice. In the first session of endoscopic retrograde cholangiopancreatography (ERCP), a nasobiliary catheter was placed, and carcinoma of the mid bile duct was pathologically confirmed ( $\triangleright$ Fig. 1). Given that there was no evidence of metastasis on imaging studies, a second session was conducted to assess lateral tumor spread and determine the required extent of surgical resection. After biliary cannulation, a 0.035-inch guidewire (Jagwire; Boston Scientific, Natick, Massachusetts, USA) was passed to the bile duct at segment II (B2). A biopsy forceps with 2-mm-wide cups (Radial Jaw 4 pediatric; Boston Scientific) was used to acquire tissue specimens at the left hepatic duct and the communication of the hepatic ducts. However, the dilated left hepatic duct inhibited the forceps being advanced into the right lobe. Therefore, we added a looped nylon thread to one cup of the forceps ( $\triangleright$ Fig.2) and inserted the forceps with the loop over a guidewire placed in B8 (• Fig.3). The forceps was successfully passed to $\mathrm{B} 8$, and targeted biopsy was achieved from the right hepatic duct. Based on positive histology in this biopsy of the right hepatic duct, hepatopancreatoduodenectomy was scheduled.

The Radial Jaw series has been among the most widely used biopsy forceps, with the forceps having hole(s) in each cup, through which a looped thread can readily be passed. Despite the reported effectiveness of cholangioscopy-guided biliary biopsy [4], this modality is limited by high costs and the unavailability of large biopsy forceps. The "zipline" technique presented here would facilitate biliary biopsies during ERCP at minimal additional costs ( $\triangleright$ Video 1 ).

Endoscopy_UCTN_Code_TTT_1AR_2AD

Competing interests

The authors declare that they have no conflict of interest.
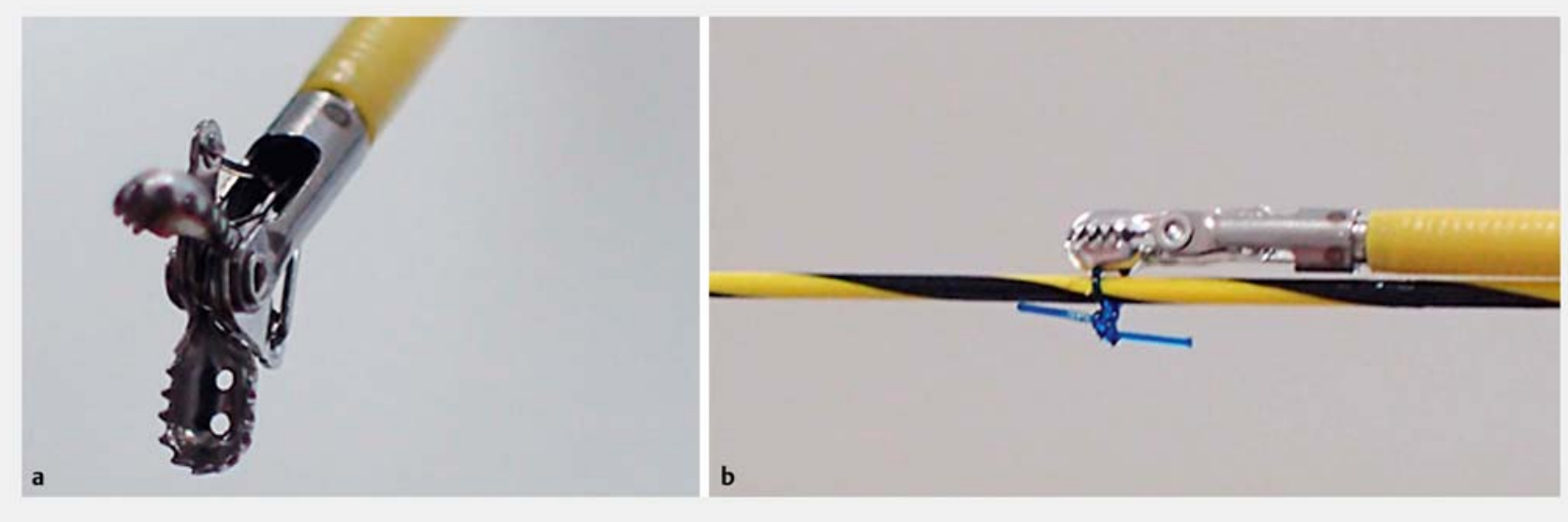

Fig. 2 Photographs of the Radial Jaw 4 pediatric biopsy forceps showing: a the presence of two holes in each cup, which are designed to facilitate tissue acquisition; $\mathbf{b}$ a looped nylon thread passed through the holes of one cup of the forceps, which allows the forceps to be advanced over a guidewire. The technique can also be applied for biopsy forceps with one hole in each cup. 

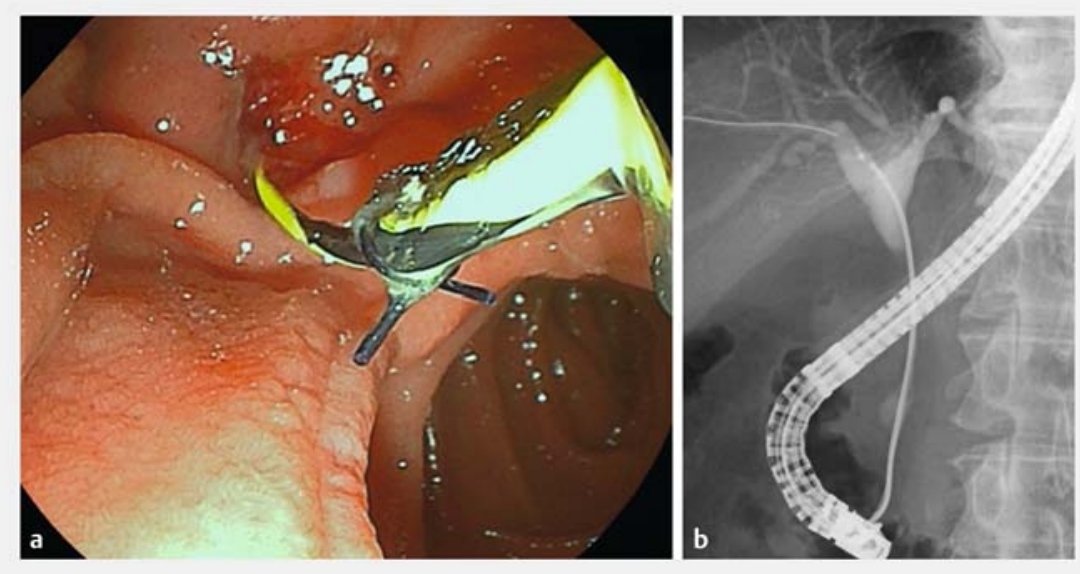

- Fig. 3 The "zipline" technique for targeted biopsy of the right intrahepatic bile duct. a Endoscopic image of the threaded forceps being advanced over a guidewire. b Radiographic image showing the biopsy forceps with a looped nylon thread that was successfully passed into the right intrahepatic bile duct, which allowed sufficient tissue specimens to be obtained from the right hepatic duct.

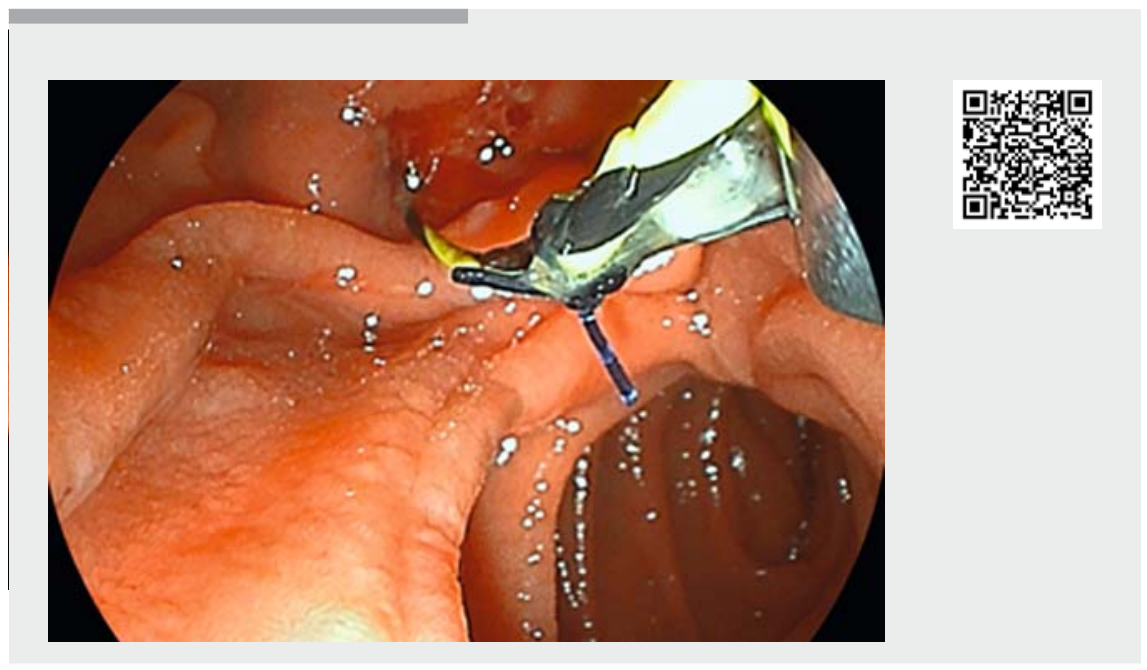

$\checkmark$ Video 1 The "zipline" technique that facilitates biliary biopsies during endoscopic retrograde cholangiopancreatography.

Tsuyoshi Hamada ${ }^{1}$, Naminatsu Takahara', Yousuke Nakai ${ }^{1,2}$, Sachiko Kanai ${ }^{1}$, Tomotaka Saito' ${ }^{1}$, Kazuhiko Koike ${ }^{1}$

1 Department of Gastroenterology, Graduate School of Medicine, The University of Tokyo, Tokyo, Japan

2 Department of Endoscopy and Endoscopic Surgery, Graduate School of Medicine, The University of Tokyo, Tokyo, Japan

\author{
Yousuke Nakai, MD, PhD \\ Department of Endoscopy and Endoscopic \\ Surgery, Graduate School of Medicine, \\ The University of Tokyo, 7-3-1 Hongo, \\ Bunkyo-ku, Tokyo 113-8655, Japan \\ Fax: $+81-3-58009801$ \\ ynakai-tky@umin.ac.jp
}

[1] Sun B, Moon JH, Cai Q et al. Review article: Asia-Pacific consensus recommendations on endoscopic tissue acquisition for biliary strictures. Aliment Pharmacol Ther 2018; 48: 138-151

[2] Chathadi KV, Chandrasekhara V, Acosta RD et al. The role of ERCP in benign diseases of the biliary tract. Gastrointest Endosc 2015; 81: 795-803

[3] Kawakami H, Kuwatani M, Abe Y et al. A guidewire-assisted biopsy technique to assist advancement through a biliary stricture to perform selective mapping biopsy. Endoscopy 2015; 47 (Suppl. 01): E217-E218

[4] Ogura T, Imanishi M, Kurisu Y et al. Prospective evaluation of digital single-operator cholangioscope for diagnostic and therapeutic procedures (with videos). Dig Endosc 2017; 29: 782-789

\section{Bibliography}

DOI https://doi.org/10.1055/a-1015-6609

Published online: 8.10.2019

Endoscopy 2019; 51: 236-237

(c) Georg Thieme Verlag KG

Stuttgart · New York

ISSN 0013-726X

\section{ENDOSCOPY E-VIDEOS \\ https://eref.thieme.de/e-videos}

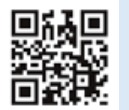

Endoscopy E-Videos is a free access online section, reporting on interesting cases and new

techniques in gastroenterological endoscopy. All papers include a high quality video and all contributions are freely accessible online.

This section has its own submission website at

https://mc.manuscriptcentral.com/e-videos 